\title{
Strategic Planning Under Severe Constraints In A State College
}

Jerry L. Geisler, (E-mail: j_geisler@mscd.edu), Metropolitan State College of Denver Debbie J. Gilliard, (E-mail: gilliard@mscd.edu), Metropolitan State College of Denver

\begin{abstract}
This paper examines the difficulties of strategic planning under severe constraints in a state college. Constraints include the planning models available, the governance structure of the college and other externalities, and a not-for-profit model of constraints by Newman and Wallender. After presenting the planning challenges, we discuss approaches to be used by institutions facing similarly constrained environments.
\end{abstract}

\section{INTRODUCTION}

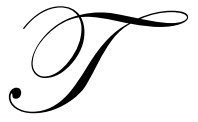

here are about 4600 colleges and universities in the United States. Like other institutions they struggle with strategic management. The focus of this paper is on strategic planning as a subset of the strategic management process. There are questions to be asked about the process. Would a strategic management model from business need to be changed to use it in a not-for-profit organization? If changes in the process are needed, what portions would be changed? Would the not-for-profit require an entirely different model?

Perhaps the issues go beyond mere process, i.e., the governance structure of a public institution may so constrain the use of a model that another approach must be used. It goes without saying that nearly all institutions would have some kind of planning system that results in a strategy. How a strategy is derived is the point here. The effective use of a strategy is a different consideration. Ultimately, the effectiveness of a strategy may be the result of the approach to making it and the strategy's fit with the internal and external environments.

From the strategy literature, Chaffee (1985) presented three models of strategy: linear, adaptive, and interpretive. The linear model focuses on planning, a methodical, directed, sequential action. The focus is on long term goals, adopting courses of action, and allocating resources. The adaptive strategy model was defined by Hofer as: "concerned with the development of a viable match between the opportunities and risks present in the external environments and the organization's capabilities and resources for exploiting these opportunities. Compared to the linear model, the adaptive model requires continuous monitoring of the environment and making changes simultaneously; a focus on means rather than goals; incorporates subtle changes in style, marketing, quality, and nuances instead of just products and markets, has less emphasis on advance planning (this point means that planning may be less centralized in top management); and the environment is considered to be a complex organizational life support system, consisting of trends, events, competitors, and stakeholders."

The interpretive strategy model parallels recent interest in corporate culture and symbolic management outside the strategy literature. A recurring theme suggests that the model is based on a social contract which portrays the organization as a collection of cooperative agreements entered into by individuals with free will. The organization must rely on attracting enough individuals to cooperate in order for a mutually beneficial exchange to occur. This model would not apply for developing strategy in a public university. The reasoning for that conclusion is furnished by Nemetz and Cameron (2006) in a summary of environmental influences: 
Administrators of higher education are increasingly under duress, with pressures from:

1. budget retrenchment, accountability, market forces, and outcome measurement

2. antagonizing a system built on generously pensive rumination and unquestioned

3. relevance to societal prosperity. At the same time that cost containment is a dynamic

4. driving universities, expectations are increasing several-fold, with greater access,

5. responsiveness to nontraditional student populations, expanding university boundaries,

6. and improved quality at the forefront of demands by public policy makers.

Smith and Ferris (2002) presented more support for the conclusion based on changes in the internal management of universities following periods of stability and/or decline. Responses to declines are usually cost containment which results in resistance to change, low morale, conflict, turnover, centralization, and lack of longterm planning.

Other environmental changes were noted by Julian and Ofori-Dankwa (2006) who wrote that the external environment of business schools is becoming more turbulent. They suggest that technological, societal, and industry changes are undermining the stable, continuous environment found in the past in higher education. New technology is changing the delivery of college instruction especially in the arena of on-line and distance learning classes. There is greater competition from private institutions (such as Phoenix University). Major leading universities (such as Stanford, Duke, NYU, and Columbia) are offering degrees on-line making their programs more accessible to all students. The number of corporate universities increased from 400 to more than 2000 between the years 1988 and 2001. State funding is changing also. Many states decreased funding for higher education between 2002 and 2006. Moreover, the highly bureaucratic structures in higher education may restrict innovation and support incremental changes and improvements.

\section{METROPOLITAN STATE COLLEGE OF DENVER (MSCD)}

We are examining the process of strategic planning in a state college to identify constraints, analyze the process being used, and speculate as to the effectiveness of its usage. Metropolitan State College of Denver (MSCD) was established in 1963 by the Colorado Legislature that mandated it to be a comprehensive, baccalaureate degree granting institution serving the six-county area around Denver. It was accredited by the North Central Association of Colleges and Schools in 1968. During the period 1993-2003, the College was headed by a president that identified themes annually in lieu of strategic planning. For the next few years the College had interim and acting presidents.

In June, 2005, a new president was appointed and stated that during the first two years of his tenure, MSCD would develop a comprehensive strategic plan that would chart its course over the next 10 years. During the Academic-Year 2005-2006 a number of events in the strategic planning process occurred: 1) In summer 2005 academic vice presidents and deans were involved in a two-day strategic planning training program. 2) In the fall, the president identified a vision for MSCD and identified four broad initiatives that would help define short-term goals. The vision is: "MSCD will be the preeminent urban baccalaureate college in the country." The four initiatives are: a) Develop a faculty cadre that demonstrates commitment to teaching, b) Complete a review of what it means to be a modified-open admissions institution, c) Develop partnerships with Denver Public Schools and area community colleges, and d) Develop an interdisciplinary environment. 3) A strategic planning task force was organized with representatives from administration, faculty, and staff. The Faculty Senate President and the Interim Vice President of Academic Affairs chaired the task force. 4) One-hour presentations on the strategic planning process were made to department chairs and invitations given to assist them developing departmental plans. By the end of the 2005-06 AY, major strides had been made in the strategy formulation process which appear primarily to operationally define the president's four initiatives. Recently, the Associate Provost for Institutional Planning issued a directive that all departmental and school plans must use the four themes as the focal point. 


\section{MSCD'S EXTERNAL GOVERNING BODIES}

In order to better understand the constraints placed on the strategic planning process and their impact on strategy formulation, it is necessary to examine the multiple sponsors and influencers that may impact MSCD. The following is a review of these major entities.

The Colorado Legislature. When MSCD was established, the statute stated that MSCD would be a comprehensive baccalaureate degree granting institution with modified open admissions standards. The statute specifically states that "MSCD will offer a variety of liberal arts and science, technical, and educational programs. The college may offer a limited number of professional programs. MSCD shall not offer graduate programs." The statute defined MSCD's mission statement and role as a teaching, not a research, institution. The Legislature passes laws and sets the amount of state funds that institutions receive, enacting the College Opportunity Fund for this purpose. Also, it imposes limits on how much tuition may increase annually.

The Colorado Commission on Higher Education (CCHE). This organization was established in 1965 by the state legislature and has an 11 member board appointed by the Governor and confirmed by the Senate. Among its duties CCHE will: review and approve degree programs, establish a formula for distributing higher education funds, approve capital construction requests, administer financial assistance programs, administer off-campus programs, determine institutional roles and missions, and establish statewide admission and enrollment policies. Two recent initiatives implemented by CCHE are the Quality Indicator System to ensure the Colorado institutions of higher education meet performance standards and goals and an initiative to ensure that all general education courses are interchangeable among Colorado institutions.

Board of Trustees. In June 2002, the Governor of Colorado signed a bill establishing an independent Board of Trustees for Metropolitan State College. Prior to June 2002, MSCD's Board governed four state colleges, MSCD and three in rural locations. As a member of the college system, MSCD received a formula-driven resource allocation that was perceived to be inadequate for the size of its enrollments and urban standing.

The "Trustees have full authority and responsibility for the control and governance of the College, including such areas as finance, resources, academic programs, the library, curriculum, admissions, role and mission, personnel policies, etc.," (Handbook 2006). The Board also "has the sole responsibility and authority to formulate policy for the College" (Handbook, 2006). Since its establishment, the Board of Trustees regularly approves promotion \& tenure decisions, substantive changes to programs/curriculum, faculty salary administration, tuition and fees, the annual budget, etc. In 2006 legislation was passed that defined the political affiliations of Board members.

Auraria Higher Education Center (AHEC). AHEC was established to maintain the campus facilities shared by MSCD, University of Colorado-Denver, and the Community College of Denver. It is responsible for building maintenance, scheduling of classrooms, campus-wide media services, the Auraria Bookstore, the Auraria Library, campus parking, campus police department, and purchasing. Annually, each of the three institutions pay a percentage of revenues to AHEC.

North Central Association of Colleges and Schools (NCA). MSCD is accredited by NCA and must have in place the policies and processes necessary to maintain accreditation and meet General Institutional Requirements. The five criteria for accreditation are (NCA 1997 report): 1) The institution has clear and publicly stated purposes that are consistent with its mission. This is met through the institution's open enrollment policy, community partnerships, evaluation of faculty's teaching efforts, licensure programs, and off-campus course offerings. 2) The institution has effectively organized the human, financial, and physical resources necessary to accomplish its purposes. This is achieved through the governance structure, degree programs, credentialed faculty, the information system, and support entities such as the library, Institutional Research Office, Cooperative Education Internship Center, Honor's Program, and Student Services. 3) The institution accomplishes its education purposes. This is achieved through the general studies course requirements, assessment of programs, enrollment management, and financial aid for students. 4) The institution can continue to accomplish its purposes and strengthen its educational 
effectiveness. This is achieved through long-term planning and the identification of goals or initiatives. 5) The institution demonstrates integrity in its practices and relationships. This is achieved through the policies adopted by MSCD. The NCA just finished its 2007 visitation and review of MSCD.

In addition to college accreditation, many degree programs are individually accredited by the appropriate accrediting body. Examples include: Art, Chemistry Department, Music, The Social Work Program, Aviation and Aerospace Science, Civil Engineering Technology, Electrical Engineering, Human Services, Industrial Design, Mechanical Engineering, and Nursing. Each accredited degree program must meet the requirements of the accrediting body with regard to curriculum requirements and policies. According to Julian \& Ofori-Dankwa (2006) accreditation in business schools may adversely affect strategic decisions as schools attempt to develop processes and policies to meet standards of the accrediting body rather than what is appropriate action for the school given its environment.

\section{TRENDS IN FUNDING FOR COLORADO HIGHER EDUCATION}

A 1992 amendment to the state's constitution, the Taxpayers Bill of Rights (TABOR) limits the growth of state and local revenues to a restrictive formula: inflation plus the annual change in population. The impact of this amendment is that if an institution generates revenue above the formula, it may not keep the revenue. Proposition 23 , passed in 2000, has had a serious impact on state funds available for higher education. The proposition provided formula-funding for primary and secondary (K-12) education at the rate of inflation plus one percent for the first ten years of the law. It now gets a rising share of the budget at the expense of other state entities. In just one year after passage, higher education funding dropped by $\$ 170$ million.

Since the passage of TABOR in 1992, funding for higher education in Colorado has fallen from nearly the national average to 57 percent of the national average in 2004. When general fund appropriations are adjusted for inflation, the FY1994-95 system appropriation was \$5,188 per resident student and in FY2004-05 was \$3,564 per resident student for a decrease of 31 percent.

As for higher education revenues and expenses, the CCHE conducted a study of the changes from fiscal year 1991 to 2001. For the state as a whole, appropriations grew at an annual rate of 5.5 percent from $\$ 483$ to $\$ 750$ million. During the same period, however, state appropriations as a percentage of total revenue to higher education fell from 29 to 25 percent! Student tuition and fees amounted to \$376 million in 1991 and rose to $\$ 705$ million in 2001 for an annual growth rate of about 8 percent. Despite the high growth rate of tuition and fees, its percentage of the total revenue remains at just over 23 percent. Combined then, state appropriations and tuition/fees accounts for less than one-half (48.3\%) of total revenue. What about the rest?

Federal grants, contracts and advances brought in about $\$ 620$ million or 20.5 percent of total revenue. Auxiliary operating revenues accounted for another 10 percent of total revenue and indirect cost reimbursement was 3.7 percent. The point is that over one-half of the total revenue comes from other than appropriations and tuition.

These trends in state funding led Elizabeth Hoffman, former President of Colorado University and three other university presidents to warn the public of some dire consequences if the trends were to continue. They declared that Colorado public colleges and universities either would not survive or would be forced to privatize to stay alive. Hoffman stated: "Lift the spending limitations, set aside funding specifically for higher education, or let our higher education system transform itself into a private higher education system."

\section{MSCD'S APPROACH TO STRATEGIC PLANNING OVER THE PAST DECADE}

As noted earlier, MSCD and other institutions have followed a practice of planning around themes issued by the president. President Kaplan served as president of MSCD for a decade (1993-2002). During an email interview, her rationale for using themes was contained in this direct quote: "It was a reluctance to get into the time consuming and divisive traditional strategic planning process that led me into another direction. I think the themes are a quicker and a more flexible way to approach planning. The themes themselves were self-evident given the 
particular situation at MSCD in 1993. The flexibility of themes allowed the administration to move in various directions on the themes each year without being tied to a rigid strategic planning schedule."

The North Central Accreditation Report of 1997 indicates that MSCD follows a "top down and bottom up" model for planning. The four planning themes in 1996 were: academic excellence, enrollment management, diversity management, and technology. The report indicated that MSCD had committed significant funds to each of the four themes, especially to technology. There were a number of task forces or committees that developed objectives and timetables related to three of the four themes. The report also indicated a concern as to the lack of initial involvement of faculty and staff in the early phases of thematic planning which resulted in a reduced level of faculty and staff ownership of the themes. President Kaplan responded to that finding in a follow up letter: "The College's planning themes were selected after extensive conversations with internal and external stakeholders."

The short summary given above reflects a managerial choice of how planning themes were implemented at the college level. As a style, it was top down rather than bottom up. Instead of providing direction to the three schools by having them plan around the themes, the president gave direction through task forces and committees with campus-wide membership. This accomplished a great deal for MSCD, but may have left programs without specific direction although the results of initiatives were found everywhere: from smart classrooms to upgraded computer facilities in laboratories and offices.

The current president's themes are: prepare students for success in their education, career, and life; provide a high-quality educational experience; engage, collaborate, and work with the community; and embrace and promote diversity. As noted previously, the planning process will encompass these themes at the unit level for strategic planning. This is the first direct link between institutional and programmatic planning at MSCD. Now that MSCD's external influences have been presented, along with its planning methodology, it is time to examine constraints imposed by the Newman and Wallender Model for planning in not-for-profit organizations.

\section{THE NEWMAN AND WALLENDER'S MODEL}

We chose this model because it has the potential to answer some of the questions that arose as we examined strategic planning at MSCD. Many of the apparent restrictions on planning are clear from the presentation of the governance structure and the deteriorating state funding stream. The Newman and Wallender Model (Wheelen and Hunger, 2004) is aimed at not-for-profit organizations and discusses their ability to engage in the typical strategic management process of stating a mission and vision, creating clear goals, deciding on a competitive strategy, implementing the strategy, and evaluating the results and making any changes necessary. They identify constraints that require organizations to modify the strategic management process by taking into account the impact of constraints on the process and, thus, the impact of external entities on the strategy of the not-for-profit organization. Specifically, the constraints listed by them include:

1. Service is often intangible and hard to measure. Not-for-profits may develop multiple objectives in order to satisfy multiple sponsors.

2. Client influence may be weak.

3. Strong employee commitments to professions or to a cause may undermine allegiance to the organization employing them.

4. Resource contributors may intrude on the organization's internal management.

5. Restraints on the use of rewards and punishments may result from constraints 1, 3, and 4 listed above.

They also identify four complications to the strategy formulation process that not-for-profit organizations will encounter:

1. Goal conflicts interfere with rational planning. Inconsistent goals may result in a need to meet multiple sponsors' expectations.

2. An integrated planning focus tends to shift from results to resources. Outputs of services may be hard to measure thus resulting in a greater focus on resources which are easier to measure. 
3. Ambiguous operating objectives create opportunities for internal politics and goal displacement. This may result in an organization ignoring the needs of the client and focusing on the expectations of sponsors.

4. Professionalization simplifies detailed planning but adds rigidity.

Now we will use above constraints and complications as criteria to examine their impact on the strategic management process and strategy formulation at MSCD. The time frame for the analysis will be just over ten years of institutional history so that the strategic implications for MSCD may be identified. This next section will focus on the specific impact of constraints on strategic planning at MSCD.

\section{IMPACT OF CONSTRAINTS ON STRATEGIC PLANNING.}

The first impact is derived from the fact that the service provided is intangible and difficult to measure. Institutions may develop multiple service objectives to satisfy multiple sponsors. At MSCD, and many institutions of higher education, it is difficult to measure the value of a degree, the quality of the courses, and what students have learned. As noted in the previous section, MSCD has many "sponsors" in the form of governing bodies or agencies. The Colorado Commission on Higher Education requires that each institution in Colorado sign a Performance Contract in an attempt to ensure quality 'service' to customers. The 2005 MSCD Performance Contract includes expectations such as increased retention rates of students, increased graduation rates, increased enrollment of underserved students (e.g. low income \& minority), having institutional programs in place (e.g. assessment tests for math, reading and English placement, first year seminars for freshman, peer educations, bridge program for at-risk students, intervention program, a writing center, and a tutoring center), the core curriculum program, reports of grade distributions, the number of faculty teaching core courses, control of costs, the Teacher Education program requirements, and making resources available for high demand programs (e.g. nursing and K-12 education).

The purpose of these requirements is to ensure that accountability measures are in place relative to the cost and quality of post-secondary colleges like MSCD. To this point, MSCD has not attracted large donors with programmatic intentions that are often a major source of multiple service objectives. The primary challenge that MSCD faces, then, is to anticipate and satisfy the directives of governing bodies.

The second impact on strategic planning is weak client influence. Customer influence tends to be weak in not-for-profit institutions typically because clients' payments are a small source of funds. At MSCD, customer influence tends to be weak even though student-paid tuition constitutes approximately $55 \%$ of the total budget while $45 \%$ of the budget came from state funds in 2006. There is a large number of competitors in the immediate area, and it is too soon to tell how the College Opportunity Fund will affect MSCD's revenue from the state. Under the new COF system, an annual allocation of $\$ 2400$ follows a student to the college of his or her choice.

The service provided by MSCD - undergraduate degrees - is more likely to be defined by external stakeholders such as CCHE, the Board of Trustees, or degree accrediting associations rather than by students. One reason for this may be the assumption that students don't know what coursework should be required or is most beneficial for a degree while the faculty and other external entities do have knowledge of appropriate requirements. Student influence may come in the form of evaluations of faculty as it is expected that to be tenured or have a contract renewed faculty members should demonstrate high quality teaching. As a non-residential campus, Auraria students do not often participate in collective activities like student government so their influence is limited.

Employers are an indirect client while hiring MSCD's graduates. The primary vehicle for hiring students is as interns through the Co-op Program. The Auraria campus does not offer a traditional placement marketplace for students and employers. Some employers give input to departments via surveys through the program review process. This allows departments to get employer assessments of the knowledge and skills possessed by students who are two to five years out of college. If employer expectations are not being met, a program could be modified accordingly. 
The third impact is that strong employee commitment to the professions may undermine allegiance to the college. During their graduate work and academic employment, most faculty members usually become affiliated with a professional organization that is related to the degree field. Professional organizations typically define the type of research appropriate for the profession, host annual meetings for faculty and practitioners interested in the field, publish premier academic journals, influence education in the program, and influence the values/standards of professionals in the field of study.

We have no measurement of this at MSCD and consider it not to be a strong constraint, although some effects of commitment to the profession may be seen in course and program requirements. Often the faculty overseeing a degree program and developing course content depend on the 'profession' to identify content and do not analyze the impact on other degree programs. A specific example occurred in the School of Business regarding the content of a business ethics course taught in the Philosophy Department. The Philosophy faculty looked to the profession for guidance on course content with little regard for what the business faculty believed students should learn about business ethics.

A more oblique classification of allegiance might be what we call "independent contractors." A definition of an independent contractor is that outside consulting and other activities are the main interest while a teaching position funds the practice, both in monetary terms and in time available. Again, no data are available as to how many faculty members consider themselves to be independent contractors, but at least in the School of Business the perception is that the percentage is high. If true, perhaps it would mean that some faculty members may practice their professions at the expense of the institution. To any extent, however, it detracts from commitment to MSCD and reduces the time that could be spent on planning and other matters.

The fourth impact comes from resource contributors that may influence the college's internal management. The major external funding source for MSCD is the state legislature. The legislature and its policy implementing body, CCHE, do influence many decisions and actions at MSCD. As stated above, the legislature determines the amount of funds to be allocated to state colleges and universities while the CCHE influences goals, programs, admission policies, capital constructions projects, etc. These requirements can inhibit actions and/or influence what actions are taken in efforts to reach goals set by the institution. Because the stakes are high in terms of resources, the perception is that the system micromanages MSCD. This tends to constrain the breadth and depth of strategic planning activities that can be undertaken by MSCD's administrators. For example, MSCD's mission is derived from its charter provided by the legislature. Only the legislature can change the mission statement.

The last impact on strategic planning is that constraints may influence the use of rewards and punishments. MSCD is a low-cost leader, perhaps not by strategic intent, but merely because it receives limited resources. The ratio of full-time to part-time faculty has become dangerously low, for example. Base salaries are below benchmark averages and annual merit increases are small. Presently, it is not possible to reward extraordinary achievements as the evaluation process for compensation purposes treats all of those in a rating class the same.

Punishment for lack of action or failure is minimal because of the approval process. Many layers of decision makers are involved in nearly every decision, so there is little repercussion for things gone awry. Each level attempts to cover itself. Accrediting institutions may deny renewal of accreditation or the legislature may decrease funds to an institution but many remedial processes are in place to minimize these potential punishments. Based on the constraints in place, MSCD is not rewarded for meeting and exceeding expectations stated in the Quality Indicator Contract with CCHE or meeting expectations of the Board of Trustees.

Clearly, Newman and Wallender's constraints are at work at MSCD. As are those noted by Nemetz and Cameron (2006) who wrote: "Efficiency is far more important than high-mindedness in a constrained environment. Thus, the university is a system increasingly at odds with itself, being pulled in multiple directions at the same time its seemingly reluctant faculties seek to stay firmly anchored in the norms upon which their profession is built." 


\section{IMPACT OF CONSTRAINTS ON STRATEGY FORMULATION}

Strategy formulation includes the activities of developing a mission statement, setting goals and identifying a strategy. We should point out that because of the former president's thematic approach to planning MSCD has little experience in using the prescribed approach to strategy formulation. How would MSCD's strategy formulation be affected by Newman and Wallender's four factors? The factors are: goal conflicts interfere with planning, integrated planning shifts focus from results to resources, ambiguous objectives lead to internal politics and goal displacement, and professionalization simplifies planning but adds rigidity. Each of these will be discussed in turn.

Regarding goal conflicts in not-for-profit organizations, at MSCD each external entity has areas of oversight and each identifies goals or expectations. Some goals are very specific, such as retention and graduation rate expectations identified by CCHE. Other external entities do not set specific goals, but do state general expectations which results in general and ambiguous goals. This occurred at MSCD in 2005 upon arrival of a new president who stated the very general goals: hire more faculty members, review what it means to be a modified open admissions institution, develop partnerships with the Denver Public Schools and community colleges, and develop an interdisciplinary environment. Ambiguous goals are difficult to achieve as measurement is problematic. At MSCD ambiguous goals appease external stakeholders while giving the appearance that each goal was achieved because measurement is difficult if not impossible.

Because of ambiguous goals and the difficulty in measuring results, Wheelen and Hunger (2004) suggest that not-for-profit institutions will shift their planning focus to resources and inputs from outputs (results). This is true at MSCD. A great deal of focus is on the monies available each year. State funds decreased $7.4 \%$ from 2002 to 2003; decreased 11\% from 2003 to 2004, stayed even in 2005; and increased 6.6\% from 2005 to 2006. During the same time- frame, monies from tuition increased $11.3 \%$ between 2002 and 2003; increased $8.4 \%$ between 2003 and 2004; increased 3.9\% between 2004 and 2005; and increased 9.6\% between 2005 and 2006. Total revenues received in 2006 are about $\$ 7,000,000$ more than revenues received in 2002. Costs increased at the same time. To operate within budgeted revenues many cost cutting actions were undertaken: new faculty were not hired and a greater reliance was made on less expensive adjunct (part-time and temporary) faculty members, equipment and technology replacements were postponed, the number of administrators decreased, and overall MSCD did more with less money. In the process, the full-time: part-time ratio for coverage of classes went from 65:35 to 35:65. During this period student enrollment increased so there were more demands on limited resources.

The third factor is that ambiguous objectives lead to opportunities for internal politics which leads to maneuvering for personal ends. A specific example of this can be provided. At MSCD a board member initiated a drive to develop an integrated entrepreneurial program. A task force was developed, interaction with local community leaders was undertaken, and a draft proposal has been developed. Although this may result in a program beneficial to students and the local business community, many questions may be asked --- What goal does this initiative help achieve? Does this fit with the long term vision defined by the president? Will the initiative continue to be developed after the departure of the Board member? What impact does this have on other programs at MSCD? Will there be resources available to continue this initiative into the future?

Finally, the model suggests that professionalization simplifies planning but adds rigidity in that professional values and traditions can prevent institutions from changing behavior. At MSCD tradition is very much in place. Some degree programs have not changed in the past 10 years unless mandated by legislation or an external entity (such as the legislature). There is little incentive to make degree program changes and no apparent reward. The formalized bureaucratic process to make changes (approval by the Board and CCHE) make it a daunting project for faculty to undertake. Moreover, there is no state funding stream for new programs. Funds flow only after enrollments occur in the new program. The impact of the College Opportunity Fund system leaves even this tenuous funding link in doubt. Thus, change is slow unless mandated by an external entity such as an accrediting body. 
At MSCD the general studies course requirements have been unchanged for 15 years. As a result of a mandate by CCHE, these course requirements are now being reviewed and changed. A recent change undertaken in the Secondary Education degree program was initiated by the Colorado Department of Education, CCHE, and various professional teachers associations. Specific changes in the degree include: a greater emphasis on reading, $126 / 128$ credit hours required for graduation instead of the 120 credit hours designated by CCHE, and requiring Secondary Education be the accepted minor for students rather than selecting a minor in a another teaching field. The requirements of a professional organization may have influenced the accounting degree program at MSCD, namely that students would have to have 150 credit hours in order to sit for the CPA exam. Most other states have adopted this 150 credit hour requirement.

\section{CONCLUSION}

We have painted a rather bleak picture of environmental constraints and inhibitors of strategic management at MSCD. Is MSCD different from the thousands of other institutions? No, and that is the point. All institutions face a difficult, but not impossible, planning task. In fact, the game will continue whether we play well or not. This section is aimed at playing it as well as possible. Several approaches to that end are presented and discussed.

First, the temptation might be to see planning as futile, i.e., everything is determined by someone or something else so there is little point in trying. Be assured that the competition is engaging in planning so not to do so could have serious consequences. Research findings show a positive relationship between planning and effectiveness (Wheelen and Hunger, 2004).

Second, although there is little information concerning the number of institutions using themes as an approach to planning, themes may be a reasonable starting point. One impressive advantage of using themes is the ability to be more directive and incisive in what to accomplish and when to accomplish it. Themes are a top-down management style and allow an institution to change faster. This was demonstrated at MSCD when the theme "technology" was implemented by forming College-level task forces to plan and execute the theme. The focus became faculty and staff participation to accomplish the theme. This approach speeded up the process while reducing the prospects of a failed implementation.

There are three drawbacks that must be overcome if themes are to be used over the long term. First, the themes are likely not based on a situational analysis, i.e., internal strengths and weaknesses and external opportunities and threats. Good strategies must be based on the strategic fit between the internal and external environments. The second drawback is that themes are actually strategic objectives disguised as strategies. Usually they are not stated in measurable terms and may have an obtuse reference to the mission statement if at all. The third issue is that, over the long term, departments and schools/colleges will probably not get strategic direction to foster innovation and change in academic programs from which the institution may establish its reputation for excellence in programs and instruction.

The third major approach to planning follows from the classic strategic management model: develop vision and mission statements; perform external and internal audits; establish long-term objectives; generate, evaluate, and select strategies; and measure and evaluate performance (David, 2005). Using this, or a similar process, on a regular cycle would pay benefits for most institutions. Certainly there is a need to pay attention to strategies and their implementation. The external pressure on universities to "prove" that they deliver value to students continues to grow (Kingsbury, 2007). This model, however, tends to be reactive rather than proactive.

The fourth approach, Hofer's adaptive strategy model (Chafee, 1985) takes an open systems view of the institution's relationship with its environment. The environment is more dynamic making predictions more difficult. This makes the task of strategic management one of simultaneously changing the organization with changes in the environment. Such changes may be caused by competition, trends, events, and stakeholders. This model requires continuous monitoring of the environment with a capacity for making appropriate changes in strategy as the need arises. It is a proactive model. 
Finally, becoming involved in politics is very necessary. Coalitions have formed around the need to influence how the State of Colorado distributes its revenues. As noted earlier, by law some agencies are receiving larger portions of state funds while higher education is getting a smaller portion. Because the budgetary process is essentially a zero-sum game, the politics are intense. Unfortunately the outcome is likely to only delay or limit the decline and less likely to increase the share to higher education. At best the political approach is a defensive strategy, but leaving the outcome to chance could be disastrous.

In conclusion, the strategic planner in higher education is in a tough situation. Overcoming environmental constraints, internal issues and limitations, and scarce resource inputs are a monumental challenge. Not to engage in strategic planning is not an option. It is the only weapon available. .

\section{REFERENCES}

1. Chaffee, Ellen E. 1985. Three Models of Strategy. Academy of Management Review, 10(1), 89-95.

2. Colorado Commission on Higher Education. 2006. Accessed on-line at http://metroconnect.mscd.edu

3. David, Fred r. 2005. Strategic Management: Concepts and Cases, New Jersey, Pearson Education, Inc.

4. Edge, Jayne W. 2004. The Need for Strategic Planning in Academia. THE Journal, 32 (3), 40-42.

5. Julian, S.D. \& Ofori-Dankwa, J.C. 2006. Is Accreditation Good for the Strategic Decision making of Traditional Business Schools? Academy of Management Learning \& Education, v(2), 225-233.

6. $\quad$ Kingsbury, Alex 2007. The Measurement of Learning, U S News \& World Report, March 12, 53-57.

7. Nemetz, Patricia L. \& Cameron, A. 2006. Higher Education Out of Control: Regaining Strategic Focus in an Age of Diminishing Resources. Academy of Management Learning \& Education, 5(1), 38-51.

8. $\quad$ NCA Report of the 1997 Accreditation Visit. 1997.

9. Smith, S.S. \& Ferris, G. 2002. Human Resources Strategy and Planning in Higher Education. Human Resources Strategy and Planning in Higher Education. 12(4), 13-25.

10. Trustees Policy Manual, June 2006. Accessed On-line at http://metroconnect.mscd.edu

11. Wheelen, T. \& Hunger, D. 2004. Strategic Management and Business Policy. New Jersey: Pearson Education, Inc. 